\title{
Persons, Post-persons and Thresholds
}

\author{
Dr James Wilson, UCL, james-gs.wilson@ucl.ac.uk.
}

This is a final draft version - the definitive version is available from the Journal of Medical Ethics, doi: 10.1136/medethics-2011-100243. This article replies to DeGrazia D. "Genetic enhancement, post-persons, and moral status: a reply to Buchanan.", $J$ Med Ethics doi:10.1136/medethics-2011-100126.

DeGrazia argues that all sentient creatures have the same moral status, on the basis of a thought experiment in which a significant proportion of human beings are enhanced to become "post-persons". The key claim in his argument is that post-persons "have about as much justification in believing that they have higher moral status than persons as persons have in believing that they have higher moral status than animals".[1] If this claim is true, then unless we are willing to accept that post-persons have a higher moral status than persons, we should not accept that persons have a higher moral status than animals.

DeGrazia's main claim presupposes the falsity of what he calls the Respect View. The Respect View claims that all creatures whose morally relevant properties are sufficient to bring them over the threshold for moral personality have the same moral status. On the Respect View, having these morally relevant qualities to a higher degree does not increase moral status. If the Respect View is correct, then post-persons' mental and moral superiority will not give them a reason to think that they have higher moral status.

DeGrazia supports the idea of a threshold, but argues that it should be drawn at the level of sentience, not moral personality. I take it that his argument is that the Respect View (a) has no non- arbitrary way of drawing the line for morally relevant features other than sentience, and (b) even if there were a nonarbitrary place to draw the line, there is no reason to think that the line would be drawn at precisely the point which corresponds to ordinary human capacities. In short, either the line should be drawn in a place unfavourable to unenhanced humans, or it should not be drawn at all.

I wasn't sure whether this is supposed to be a general argument against any morally relevant properties that might be cited as justifying a difference in moral status between humans and other animals, or just the particular property which Buchanan [2] mentions in the paper DeGrazia is responding to, namely moral accountability. If it is the latter, then the argument would provide at best weak support for the claim that all sentient creatures have the same moral status. If it is the former, DeGrazia would certainly need to do more to show that the result generalises.

In previous work I argued for a Respect View which uses Rawls's two moral powers (the capacity for a sense of justice, and the capacity for a conception of the good) as the features which must be possessed to a threshold amount to give a creature the highest moral status. [3] It is unclear that such an account falls victim to DeGrazia's argument. First, these features are held to a very significantly greater degree by human beings than 
by other animals. Animals such as dogs or chickens simply do not have "the capacity to understand, to apply, and to act from (and not merely in accordance with) the principles of political justice that specify the fair terms of social cooperation", nor do they have "the capacity to have, revise, and rationally to pursue ... an ordered family of final ends and aims which specifies a person's conception of what is of value". [4] Second, whilst it is true that unenhanced human beings are very imperfect in the use of these capacities, their abilities in this regard are not negligible; and these capacities are of deep relevance for how we should treat creatures who have them.

Hence, I do not think that DeGrazia has made the case that the Respect View is wrong. And if the Respect View remains tenable, there is no reason to think the higher moral status of humans vis-a- vis animals entails the higher moral status of post-persons vis-avis persons.

It is unclear what practical import DeGrazia's proposed levelling of moral status would have, even if we accept it. On DeGrazia's view, all sentient beings have the same moral status, so invoking moral status can no longer provide any guidance when we are faced with a conflict between the interests of human beings and other animals. DeGrazia argues that we should resolve such conflicts on the basis of a consideration of the interests of the different parties rather than their moral status. Human beings (and postpersons) can be harmed or benefited in broader, deeper and larger ways than rats, and so it is legitimate to give preference to the interests of human beings.

However, it seems to me that such a move may well simply leave the basic normative dispute about how to resolve conflicts between human and animal interests intact. It looks like it will be open to the proponent of a higher moral status for humans to restate her case in terms of interests: rather than claiming that human beings have a higher moral status, she can claim that certain kinds of interests (those coming from a rational beings' projects, or those of a rational being in avoiding degrading treatment) are so important that they should always win out against any amount of conflicting interests of nonrational creatures.

In short, DeGrazia's view faces a dilemma. Either his view is compatible (at least de facto) with the kind of principled privileging of human interests that believers in what he calls the Respect View believe in, or it is not. If it is compatible, then it looks like DeGrazia will have shifted the locus of the debate about the treatment of animals, but not necessarily shifted its content or end result. If it is not compatible, then DeGrazia will be proposing a framework in which some of the deepest held views of many morally serious people cannot even be expressed.

[1] DeGrazia D. Genetic Enhancement, Post-persons, and Moral Status: a reply to Buchanan.

Journal of Medical Ethics forthcoming. doi:10.1136/medethics-2011-100126

[2] Buchanan A. Moral Status and Human Enhancement. Philosophy and Public

Affairs. 2009;37

(4):346-381 -at 360-1. 
[3] Wilson J. Transhumanism and moral equality. Bioethics. 2007;21(8):419-25.

[4] Rawls J. Justice as Fairness: a restatement. Harvard University Press; 2nd Revised edition

edition 2001: 18-9. 